\title{
Current and future of the Journal of Exercise Rehabilitation
}

\author{
Khae Hawn Kim (iD http://orcid.org/0000-0002-7045-8004
}

The Journal of Exercise Rehabilitation is supported by the Korean Society of Exercise Rehabilitation. The primary mission of the Korean Society of Exercise Rehabilitation is to aim for the scientific development of exercise rehabilitation by promoting academic researches in social, mental, and physical health welfare theory and mutual academic exchanges among scholars. The society further aspires to provide contribution to the health and welfare of advanced countries.

The Korean Society of Exercise Rehabilitation was founded in 2004 followed by launching of the official journal, the Korean Journal of Exercise Rehabilitation in 2005. After a careful consideration, the Korean Journal of Exercise Rehabilitation changed its official name to the Journal of Exercise Rebabilitation and its publication language to English since April, 2013 (Vol.: 9, No.: 2). Shortly after in October 2013, the Journal was listed in PubMed and PubMed Central. The society and the journal have been working more aggressively for the academic identification and practical application of exercise rehabilitation.

The scopes of the Journal of Exercise Rehabilitation have been on exercise rehabilitation welfare, exercise rebabilitation psychology, exercise rebabilitation pedagogy, clinical application of exercise rehabilitation, and mechanisms of exercise rehabilitation. Furthermore, the Journal of Exercise Rebabilitation has strategically included a range of integrative studies that basis the principles and applications of exercise rehabilitation with particular emphasis on behavioral therapy for the health of society. Since the English journal transition, articles from diverse themes in the area of exercise rehabilitation have been published from a variety of countries.

We have built and opened up a journal website (http://www. e-jer.org) dedicated to promote and provide scientific trends and core contents in the area of exercise rehabilitation readers of all levels from different corners of the world. We have especially focused on providing information with international journal standards and regulations for credibility of the contents and easy access by the public. For transparency and reliability of the journal, the site utilizes the online posting and peer review management systems. To provide unbiased perspectives, we have invited twenty-two experts specializing in each field from 11 different countries as members of the editorial board. The editorial board and the society have been maintaining a close contact with the editorial board members of the journal by regularly holding international conferences with globally renowned lecturers to promote globalization and internationalization.

Despite the remarkable advances in medicine and science, incurable diseases are still challenging tasks in today's society. In addition, with a rapid emergence of the aging society, increased prevalence of adult and geriatric diseases have brought variety of complications including sharp rises in the number of noncommunicable diseases and related medical costs. Moreover, since exercise has been used as a tool for the involvement in games such as Olympics, exercise related injuries have been nonnegligible. Scientific approaches to prevent and rehabilitate athletes have been proven to reduce detrimental injuries. With proven effects of exercise as both preventative and rehabilitation modality for a number of geriatric diseases and exercise related injuries, the primary focus of the journal seem inevitable. In addition, exercise is now known to exert many beneficial effects on health and possibilities for new therapeutic values and potentials.

It is our mission to further investigate and elucidate various aspects of exercise to promote prevention and rehabilitation for ex- 
isting and newly prominent complications. In addition, continuous update of the contents of the journal and the global scholastic network seem necessary toward becoming a leader in the field of exercise rehabilitation. We believe that the Journal of Exercise Rebabilitation will serve to support the academic progress in the field of exercise rehabilitation with humane responsibility to the challenges of modern society.

\section{CONFLICT OF INTEREST}

No potential conflict of interest relevant to this article was reported.

Editor-In-Chief Department of Urology, Gachon University Gil Medical Center, Gachon University School of Medicine, 21 Namdong-daero 774beon-gil, Namdong-gu, Incheon 21565, Korea E-mail: kimcho99@gilhospital.com 